\title{
Cancer survivors need evidence on how to optimize physical function
}

\author{
Michael Feuerstein
}

Received: 1 May 2009 / Accepted: 6 May 2009 / Published online: 22 May 2009

(C) Springer Science + Business Media, LLC 2009

About two months ago I was walking in Georgetown on a perfectly sunny Sunday afternoon. The sidewalk I was on had no uneven sections, and it was dry with no ice or snow. Suddenly, I was falling forward. I attempted to catch myself and just could not coordinate my legs to stop the fall. I used my right arm and shoulder to break the fall and the sidewalk won out. As I sat up on the sidewalk I was in pain and found I could not move my arm. I decided I should to drive to an ER. After the Xray and it was clear that I didn't break anything, I went home. After the fall I thought that perhaps I should have an MRI of my brain because I, like other brain tumor survivors, know the tumor can recur with no other fanfare than the occurrence of a symptom.

For months prior to the fall I noticed my balance was off and it seemed like this was happening more often than in the past. I was walking with a slower and more intentional gait and when I stood upright I often swayed to the back losing balance and needing to brace myself with one foot. I thought both motor symptoms were something that may be related to my tumor or its treatment, but the problems were subtle. As with many cancer survivors while I am probably overly vigilant, I had previously just chalked these symptoms up to "changes I just need to live with." In the back of my mind, I ignored both the imbalance and the fall until a few weeks ago. At that time, I noticed that for no apparent reason I was also hitting walls as I walked

M. Feuerstein $(\bowtie)$

Departments of Medical and Clinical Psychology and Preventive

Medicine and Biometrics,

Uniformed Services University of the Health Sciences,

4301 Jones Bridge Rd.,

Bethesda, MD 20814-4799, USA

e-mail: mfeuerstein@usuhs.mil upstairs or turned corners. I thought this was strange and so, coupled with the events described earlier and this new experience, I wanted to know if there was any change in my MRI that might explain these mild balance symptoms. I arranged to reschedule my standard six month follow up and move up my MRI and clinic visit.

On exam I had minor signs of balance problems but nothing out of the ordinary. The MRI was "extremely" stable as well. The neuro-oncology group requested a more detailed study of my cerebellum for this visit and that did not find anything remarkable either. Even the atrophy differences between the two lobes of my cerebellum had remained perfectly stable. This of course was great news, no evidence of tumor growth or for that matter any change. But what do I do about my balance problems? I was told when asking about the discrepancy that I need to realize that my cerebellum has been compromised (tumor, surgical resection, radiation, and chemotherapy), I will have balance and coordination problems and perhaps other functional changes as well from time to time, but anatomically things look completely stable. The explanation that was presented for the discrepancy between the MRI and my experience of the past several months made perfect sense to me and helped to calm my concerns. However the bottom line for me is that my balance/coordination is a problem. The staff performed a very complete work up. They addressed the pathology issue which is their responsibility. Recurrence was thoroughly investigated and ruled out. I am very appreciative.

But what can I do about the balance problems? Do I see a balance specialist? Do I try to exercise on a balance board on my own? Do I see a neurologist? Do I see a physiatrist who has experience in the manage- 
ment of balance/coordination in general and perhaps some experience with brain tumor survivors? Do I adjust as best as I can and accept that this is just a late effect without a simple clean explanation? Have I become a hypochondriac? Can I change the organization of "wiring" in my cerebellum with prolonged rehabilitation focused on balance and coordination? After all, there are data from a recent paper in Stroke that demonstrates brain change in motor areas following rehabilitation for functional restoration of the affected limb [1]. Can this occur in my case? Can I rewire areas of brain involved in balance and coordination? Do we even know if certain exercises are better than others for improving balance problems in brain tumor survivors? What are my options? Who can really help me decide? What does the scientific or clinical literature tell us? I want to find the person or procedure that will help me help myself recoup or prevent my balance from getting worse. I think that is reasonable.

We must generate evidence based information that will help many different groups of cancer survivors restore functions that are now limited. Biological constraints may interfere in certain circumstances but it's time to think "outside the box" when it comes to restoring the physical function of cancer survivors.

Specialists in functional restoration such as physiatrists, neurologists, physical therapists, exercise physiologists, psychologists, and those involved in the judicious use of CAM can offer much in terms of knowledge and approaches to maximize physical functions.

Providers do offer rehabilitation services to cancer survivors but often not in the context of cancer but rather as rehabilitation patients. There are exceptions to this for example with "oncology rehabilitation". These services appears to be a viable opportunity to optimize functional restoration however we need evidence regarding the effectiveness of these services that better inform us as to their effectiveness. We can not rely solely on "clinical common sense" or the assumption that rehabilitation improves function for many problems in others so why not in cancer survivors. In order to justify referrals and reimbursement we not only need to document the incidence of these problems in cancer survivors we need to demonstrate that such efforts truly help improve short and longer term functional outcomes in comparison to "usual care" which often is exercise or adjusting to a "new normal" in various well defined groups of cancer survivors.

An important step in this knowledge development is to define and measure functional limitations using sound principles of epidemiology. Especially at this stage of knowledge in this area we need to recognize the importance of small clinical series as well. We can also generate literature reviews that better inform us of just what factors consistently emerge as risk factors and correlates of functional limitations. We also need careful reviews of ways to optimize specific aspects of function. In areas where a sufficient number of evidence-based studies exist, it may be possible to generate systematic reviews or metaanalyses for a more precise understanding of the effects of different options [2]. All these types of reviews can better inform us of how to best approach the goal of improving function. This information would be so much more helpful to those cancer survivors who ask, "what can I do after learning that it's not the recurrence of the tumor that explains my functional symptoms?" "We just don't know" can't be the answer.

\section{References}

1. Gauthier LV, Taub E, Perkins C, Ortmann M, Mark VW, Uswatte G. Remodeling the brain: plastic structural brain changes produced by different motor therapies after stroke. Stroke 2008;39:1520-5. doi:10.1161/STROKEAHA.107.502229.

2. Egger M, Smith GD, Altman DG. Systematic reviews in health care: meta-analysis in context. 2nd ed. London: BMJ Books; 2001 . 